\section{Cultivar Pollinizer Does Not Affect} Almond Flavor

\author{
F. Dicenta ${ }^{1}$, P. Martínez-Gómez, and E. Ortega \\ Departamento de Mejora y Patología Vegetal, Centro de Edafología y Biología \\ Aplicada del Segura, Consejo Superior de Investigaciones Científicas, Apartado \\ 4195, E-30080 Murcia, Spain
}

\section{H. Duval \\ Unité de Génétique et d'Amélioration des Fruits et Légumes, Institut National de la Recherche Agronomique, Site AGROPARC, Domaine Saint Paul, BP91, F-84914 Avignon, Cedex 9, France}

\section{Additional index words. Prunus dulcis, xenia, bitterness}

\begin{abstract}
The effect of pollinizer on sweet or bitter almond flavor was studied by tasting the seeds obtained from 32 crosses between sweet, bitter, and slightly bitter parents. Out of eight female parents, two were homozygous sweet ('Del Cid' and 'Aï'); two were heterozygous sweet ('Marcona' and 'Nonpareil'); one heterozygous with an almost undetectable slightly bitter flavor ('Ferrastar'); two heterozygous slightly bitter ('Garrigues' and 'Marie Dupuy'); and one bitter homozygous ('S3067', self-compatible clone obtained in CEBAS). Each cultivar was hand-pollinated with four male cultivars: one homozygous sweet ('Ramillete'), one heterozygous sweet ('Atocha'), one heterozygous slightly bitter ('Garrigues'), and one homozygous ('S3067'). Since 'Garrigues' is self-incompatible, the cross 'Garrigues' $x$ 'Garrigues' was replaced by 'Garrigues' $x$ 'S3065' (slightly bitter clone obtained in CEBAS). Tasting of the seeds resulting from each cross resulted in the complete absence of any influence of pollinizer on flavor, which only depended on the female parent.
\end{abstract}

Although not a general phenomenon, pollen sometimes affects the characteristics of endosperm (xenia) or those of adjacent tissues (metaxenia) (Swamy and Krishnamurthy, 1980). Very little information exists as to the influence of the pollinizer on the characteristics of the almond [Prunus dulcis (Mill.) D.A. Webb] kernel. Kumar and Das (1996) observed that the pollinizer had a slight influence on fruit size and maturation period but not on other characteristics.

Amygdalin is responsible for the bitter flavor of almond seed (Conn, 1980; Frehner et al., 1990; McCarty et al., 1952; Polesello and Rizzolo, 1989). Some studies have demonstrated that the sweet or bitter flavor is a monogenic trait, with bitterness being homozygous recessive (Dicenta and García, 1993; Heppner, 1923, 1926).

Kester and Asay (1975) and Kester and Gradziel (1996) reported that sweet or bitter

Received for publication 29 Apr. 1999. Accepted for publication $17 \mathrm{Feb}$. 2000. This work was financed with the projects AGF95-0004-C02-01 and AGF98-0211-C03-02 titled "Mejora genética del almendro," from the Spanish Ministry of Education and Culture. The authors thank Mariano Gambín and José Luís Patiño for technical assistance in the experiments presented in this paper. We dedicate this work to Dr. Efigenio García, who always had a great interest in the results of this assay. The cost of publishing this paper was defrayed in part by the payment of page charges. Under postal regulations, this paper therefore must be hereby marked advertisement solely to indicate this fact.

${ }^{1}$ To whom reprint requests should be addressed E-mail address: fdicenta@natura.cebas.csic.es taste of almond is not affected by the pollinizer, but presented no data. Moreover, the large number of heterozygous cultivars in the orchards would surely lead to bitter almond seeds on sweet cultivars. On the other hand, growers occasionally report bitter almonds in sweet cultivars as a result of transfer of pollen from trees with bitter kernels.

Crane and Lawrence (1952) reported that all seeds of 'Marie Dupuy' were bitter following pollination by Amygdalus communis L. var. amara Ludwing ex DC., and Simms (1996) observed that almond trees pollinated with peach [Prunus persica (L.) Batsch] pollen produced bitter seeds. In addition, heterozygous cultivars may produce slightly bitter almonds.

This paper describes an experiment in which a series of crosses were made between sweet,

Table 1. Taste of almond seeds obtained from 32 crosses.

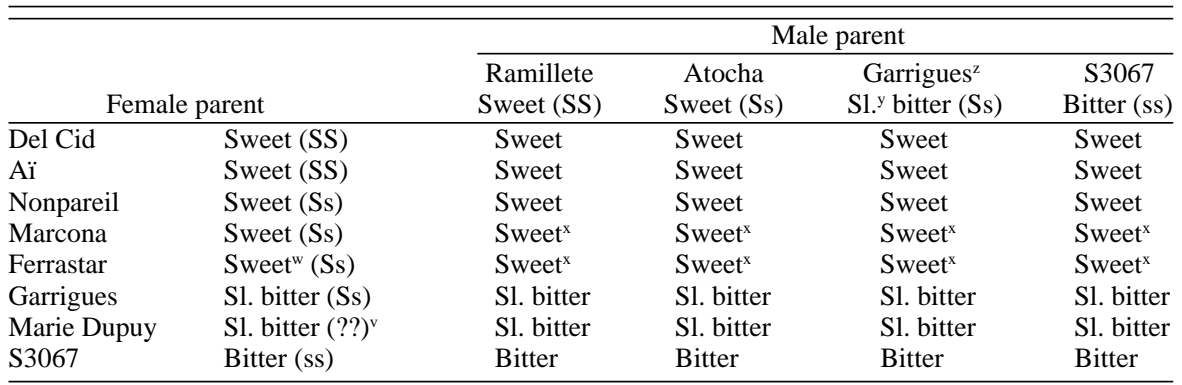

''S3065', a slightly bitter clone, was used as pollinizer in the cross with 'Garrigues'.

${ }^{y} \mathrm{Sl}$. = slightly

${ }^{x}$ Very slight (almost imperceptible) bitter taste.

w'Ferrastar' has an almost imperceptible bitter taste.

${ }^{v}$ Genotype not known, but probably Ss. bitter, and slightly bitter cultivars in order to determine if the pollinizer has an effect on the kernel flavor.

\section{Materials and Methods}

Emasculated flowers were hand-pollinated in the Departamento de Mejora y Patología Vegetal of CEBAS-CSIC, Murcia, Spain, and at the Unité de Génétique et d'Amélioration des Fruits et Légumes of INRA (Avignon, France) using pollen that had been dried at room temperature and kept at $4{ }^{\circ} \mathrm{C}$.

Eight cultivars were chosen as female parents, including 'Del Cid' and 'Aï' (homozygous sweet); 'Marcona' and 'Nonpareil' (heterozygous sweet); 'Ferrastar' (heterozygous with a very slight bitter flavor); 'Garrigues' and 'Marie Dupuy' (heterozygous slightly bitter); and 'S3067', a homozygous bitter clone obtained in CEBAS.

Each cultivar was hand-pollinated with four male cultivars: 'Ramillete' (homozygous sweet), 'Atocha' (heterozygous sweet), 'Garrigues' (heterozygous slightly bitter), and 'S3067' (homozygous bitter), giving 32 combinations. 'Garrigues' and 'S3067' were used as both female and male parents. Since 'Garrigues' is self-incompatible, the cross 'Garrigues' x 'Garrigues' was replaced by 'Garrigues' $x$ 'S3065' (slightly bitter clone obtained in CEBAS). 'S3067' is self-compatible.

The mature fruit were picked, the hulls removed, and the nuts maintained at $7^{\circ} \mathrm{C}$ until tasted. After cracking, five seeds from each of the 32 combinations were tasted by two persons.

\section{Results and Discussion}

The results (Table 1) clearly demonstrate the absence of any influence of the pollinizer on the sweet or bitter taste of the seed. No difference was observed in sweetness or bitterness between the almonds of each sample, or between crosses made between one female parent and the various pollinizers. In all cases, the maternal phenotype (sweet, slightly bitter, or bitter) prevailed. A slight, almost imperceptible, bitter taste could be detected in all seeds of 'Marcona' and 'Ferrastar', but not of 'Nonpareil', which is also heterozygous. Although 
the genotype of 'Marie Dupuy' is not known, it is probably heterozygous since it, like 'Garrigues', was slightly bitter.

Given that both the paternal and maternal genes contribute to a seed's characteristics, we would expect a tree to produce almonds of differing degrees of bitterness, depending on the genotype of the pollinizer.

Crane and Lawrence (1952) stressed that all seeds of 'Marie Dupuy' were bitter when pollinated by Amygdalus communis amara. This does not agree with our results, since this cultivar maintained its slightly bitter taste regardless of whether the pollinizer had seeds that were sweet, slightly bitter, or bitter. Given our findings, we cannot easily explain those of Crane and Lawrence (1952).

Frehner et al. (1990) demonstrated that amygdalin is not produced in the seed, but is transported from the mother plant, which supports the results obtained.

That the presence of bitter seeds on sweet almond trees results from transfer of pollen from trees with bitter seeds, as reported by previous researchers, is unlikely and may be explained by mixing of fruits from different trees in orchards where trees of both types occurred or by spontaneous mutations. The variations occasionally observed in cultivars with slightly bitter seeds (depending on the year) are probably the result of factors unrelated to the pollinizer. We therefore conclude that the maternal genotype is responsible for the taste of almond seed, and that all seeds of a given tree will be sweet, slightly bitter, or bitter, with the influence of the male parent manifesting itself only in the following generation.

\section{Literature Cited}

Conn, E.E. 1980. Cyanogenic compounds. Annu. Rev. Plant. Physiol. 31:433-451.

Crane, M.B. and W.J.C. Lawrence. 1952. The genetics of the garden plants. Macmillan, London.

Dicenta, F. and J.E. García. 1993. Inheritance of the kernel flavour in almond. Heredity 70:308-312.

Frehner, M., M. Scalet, and E.E. Conn. 1990. Pattern of the cyanide-potential in developing fruits.
Plant Physiol. 94:28-34.

Heppner, J. 1923. The factor for bitterness in the sweet almond. Genetics 8:390-392.

Heppner, J. 1926. Further evidence on the factor for bitterness in the sweet almond. Genetics 11:605606.

Kester, D.E. and R. Asay. 1975. Almonds, p. 387419. In J. Janick and J.N. Moore (eds.). Advances in fruit breeding. Purdue Univ. Press, Lafayette, Ind.

Kester, D.E. and T. Gradziel. 1996. Almonds, p. 197. In: J. Janick and J.N. Moore (eds.). Fruit breeding. Wiley, New York.

Kumar, K. and B. Das. 1996. Studies on xenia in almond. J. Hort. Sci. 71:545-549.

McCarty, C.D., J.W. Leslie, and H.B. Frost. 1952. Bitterness of kernels of almond $x$ peach hybrids and their parents. Proc. Amer. Soc. Hort. Sci. 59:254-258.

Polesello, A. and A. Rizzolo. 1989. Caratteristiche nutrizionali e utilizzazione industriale delle mandorle. Frutticoltura 4:43-50.

Simms, C. 1996. Bittersweet harvest. The garden. November, p. 724-725.

Swamy, B.G.L. and K.V. Krishnamurthy. 1980 From flower to fruit. Embryology of flowering plants. Tata MacGraw-Hill, New Delhi. 